\title{
Diarréia como Manifestação Inicial de Lúpus Eritematoso Sistêmico
}

\section{Diarrhea as Initial Manifestation of Systemic Lupus Erythematosus}

\author{
Marcos de Figueiredo Cardoso ${ }^{(1)}$, Denilson S. Franco ${ }^{(1)}$, Ana Caroline Sobral Melo ${ }^{(1)}$, Eduardo Paulino $^{(1)}$, \\ Janaína Luz Narciso-Schiavon ${ }^{(2)}$, Leonardo de Lucca Schiavon ${ }^{(2)}$, Luiz Carlos Latorre ${ }^{(3)}$, \\ Fernando da Costa Buzzoleti ${ }^{(4)}$
}

\section{RESUMO}

O lúpus eritematoso sistêmico (LES) é uma doença crônica que acomete principalmente mulheres entre a terceira e quinta década de vida, multissistêmica, freqüentemente afetando os rins e o sistema nervoso central. Os sintomas relacionados ao trato gastrintestinal, apesar de comuns, quando ocorrem abrindo o quadro clínico, raramente levam ao diagnóstico por causa de sua baixa especificidade. Foi relatado um caso de LES cuja manifestação inicial foi diarréia crônica.

Palavras-chave: lúpus eritematoso sistêmico, diarréia, perda de peso.

\section{INTRODUÇÃO}

As manifestações gastrintestinais em um paciente com lúpus eritematoso sistêmico (LES) podem estar associadas à atividade da doença, podem ser conseqüência do tratamento ou decorrentes de outra patologia associada ou não ao LES $^{(1)}$. Entre os sintomas gastrintestinais associados ao LES, os mais freqüentes são dor abdominal (secundária a serosite ou vasculite intestinal), vômitos e diarréia ${ }^{(2)}$. Entretanto, diarréia como manifestação inicial do LES é incomum, motivo pelo qual se decidiu relatar o caso.

\section{RELATO DE CASO}

Paciente de 41 anos, masculino, previamente hígido, iniciou quadro de diarréia há cerca de dois meses. Apresentava cinco evacuações ao dia, de consistência pastosa, sem restos alimentares, muco, pus ou sangue. Associado ao quadro referia também prostração, febre não aferida e emagrecimento de $10 \mathrm{~kg}$ no período. Uma semana antes

\begin{abstract}
Systemic Lupus Erythematosus (SLE) is a chronic multissystemic disease that compromises women between the third and the fifth decade and frequently evolves the kidneys and the central nervous system. Gastrointestinal symptoms are usual however, when they appear as first symptoms, they rarely lead to lupus diagnosis for its low specificity. We report a case of SLE in which the initial manifestation was diarrhea.
\end{abstract}

Keywords: systemic lupus erythematosus, diarrhea, weight loss.

da internação houve agravamento do quadro, sendo, então, admitido para investigação diagnóstica.

Ao exame físico, apresentava-se em regular estado geral, consciente, orientado no tempo e no espaço, descorado $+/ 4+$, afebril. A ausculta respiratória mostrava murmúrio vesicular diminuído discretamente em base de hemitórax direito e ausculta cardíaca normal. Abdome plano, ruídos hidroaéreos aumentados, discretamente doloroso à palpação de epigástrio, sem descompressão brusca dolorosa e sem visceromegalias. $\mathrm{O}$ exame neurológico da admissão era normal. Pele e fâneros sem alterações.

Os exames laboratoriais evidenciaram hemograma normal, creatinina $1,1 \mathrm{mg} / \mathrm{dL}$, albumina sérica de $2,5 \mathrm{mg} /$ $\mathrm{dL}$, eletrólitos normais e a urina tipo 1 exibia proteinúria $3+/ 4+$. A proteinúria de 24 horas foi de $1,5 \mathrm{~g} / 24 \mathrm{~h}$. As sorologias para HIV (vírus da imunodeficiência humana), sífilis, toxoplasmose, citomegalovírus, vírus Epstein-Barr, hepatites B e C foram negativas, assim como a pesquisa de parasitas e a cultura das fezes. A endoscopia digestiva alta

Recebido em 20/8/2007. Aprovado, após revisão, em 16/4/2008. Declaramos a inexistência de conflitos de interesse

Serviços de Clínica Médica e Reumatologia do Hospital Heliópolis, São Paulo.

1. Médico residente do Serviço de Clínica Médica do Hospital Heliópolis, São Paulo.

2. Médico do Serviço de Clínica Médica do Hospital Heliópolis, São Paulo.

3. Médico do Serviço de Reumatologia do Hospital Heliópolis, São Paulo

4. Chefe do Serviço de Clínica Médica do Hospital Heliópolis, São Paulo.

Endereço para correspondência: Janaína Luz Narciso-Schiavon, Rua Cônego Xavier, 276, 4o andar, Vila Heliopólis, 04231-912, São Paulo, SP, e-mail: janaina.narciso@uol.com.br 
foi normal e a biópsia de duodeno evidenciou relação vilo/ cripta normal e a coloração com ácido periódico-Schiff (PAS) foi negativa. O estudo contrastado do intestino delgado e o enema opaco foram normais. A retossigmoidoscopia até o cólon descendente não evidenciou alterações. A radiografia de tórax exibia discreto derrame pleural bilateral (Figura 1). A tomografia computadorizada (TC) de abdome revelou a presença de discreta ascite (Figura 2), sem outras alterações.

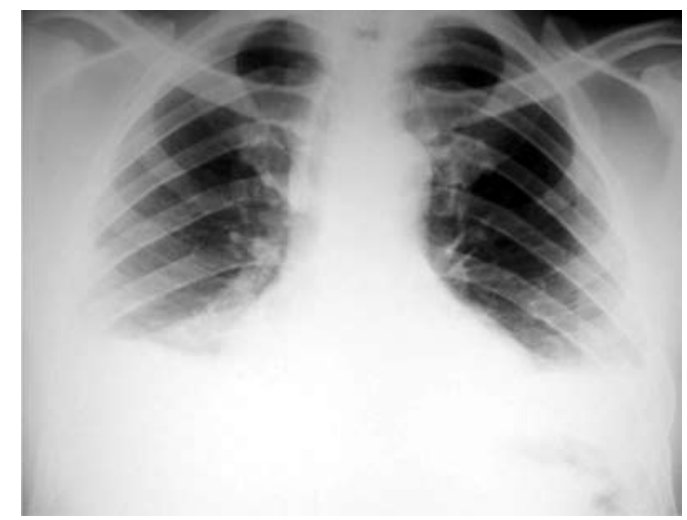

Figura 1 - Radiografia de tórax com derrame pleural bilateral.

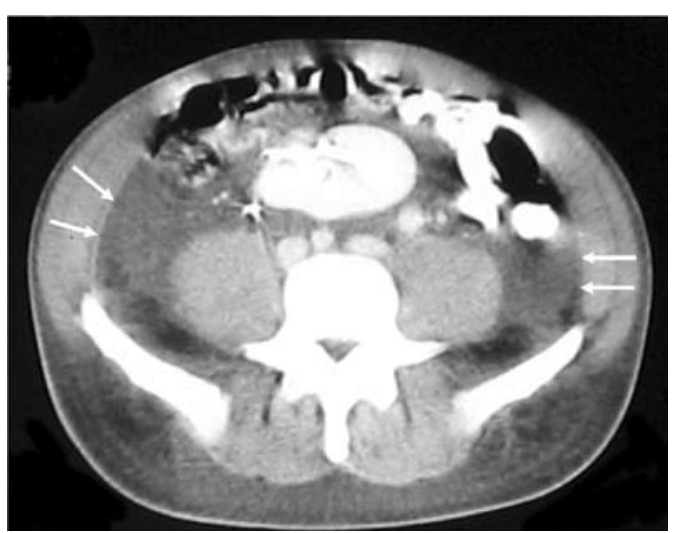

Figura 2 - Tomografia computadorizada de abdome evidenciando ascite.

Durante a investigação, enquanto aguardava a colonoscopia, o paciente evoluiu com rebaixamento do nível de consciência, mioclonias e movimentos involuntários do tipo mastigatório. A TC de crânio foi normal e o exame do liquor suboccipital revelou 18 células (93\% linfócitos) e proteína de $60 \mathrm{mg} / \mathrm{dL}$. Em virtude do quadro neurológico, proteinúria e polisserosite, foi feita hipótese de LES com provável quadro de vasculite do SNC. Os exames adicionais revelaram FAN (+) 1:360 pontilhado grosso, anti-Sm (+) 1:6.400, anti-RNP (+) 1:6.400 e todas as frações do complemento sérico estavam diminuídas. Foi realizada pulsoterapia com metilprednisolona $1 \mathrm{~g}$ por dia, durante três dias, com melhora importante do quadro neurológico e diarréico, assim como resolução da proteinúria e da serosite. O paciente recebeu alta para acompanhamento ambulatorial em uso de prednisona $1 \mathrm{mg} / \mathrm{kg} /$ dia.

\section{DISCUSSÃO}

A diarréia crônica é condição freqüente que acomete 3\% a $5 \%$ da população em geral. Com diagnóstico diferencial amplo e usualmente uma história pobre com exame físico inespecífico, a investigação das diarréias crônicas torna-se complexa ${ }^{(3)}$.

Quando o acometimento gastrintestinal está associado à atividade do LES, as causas a serem consideradas são a vasculite mesentérica e a enteropatia perdedora de proteínas $^{(2,4-7)}$. A vasculite mesentérica pode estar presente em $0,2 \%$ a $60 \%$ dos pacientes com LES admitidos por dor abdominal, e o prognóstico é usualmente ruim por causa da presença de ulcerações, hemorragia, perfuração e infarto mesentérico ${ }^{(2,4,5)}$. Pode apresentar-se como uma síndrome, caracterizada por episódios recorrentes de dor abdominal aguda, associada à hipocomplementemia, sendo reversível com imunossupressão. Histologicamente, arterite de pequenos vasos e venulite foram descritas ${ }^{(2,4)}$. O tratamento do acometimento gastrintestinal associado ao LES geralmente é clínico, por meio do uso de imunossupressores. O tratamento cirúrgico é reservado para o caso de complicações, como perfuração, obstrução intestinal ou infarto mesentérico ${ }^{(2,4)}$. A enteropatia perdedora de proteínas, caracterizada por hipoalbuminemia secundária à perda gastrintestinal, é suposta nos casos de diarréia crônica associada à hipoalbuminemia em paciente com lúpus, sem proteinúria significativa. Outras causas de enteropatia perdedora de proteína devem ser excluídas, como o linfoma e o supercrescimento bacteriano ${ }^{(6)}$. Sua patogênese é desconhecida, todavia, postula-se que um dos mecanismos envolvidos seja o aumento da permeabilidade capilar, secundário à dilatação linfática e à destruição vascular ou da mucosa, mediada por citocinas ou complemento. O diagnóstico é feito a partir da exclusão de outras causas de perda protéica e da confirmação da presença de proteína nas fezes. A boa resposta clínica ao tratamento imunossupressor contribui para o diagnóstico ${ }^{(7)}$.

Raramente, são relatadas associações entre o LES e as outras condições causadoras de diarréia crônica, como doença celíaca e doença inflamatória intestinal (retocolite 
ulcerativa e doença de Crohn), além das doenças infecciosas, como a tuberculose e as parasitoses intestinais ${ }^{(8-12)}$. Existem menos de 20 casos descritos da associação entre a doença celíaca e o LES, freqüentemente apresentando diarréia, anemia e alopécia. O diagnóstico é feito pela pesquisa de auto-anticorpos (antigliadina, antiendomísio ou antitransglutaminase), associado à presença de alterações na biópsia de duodeno distal, caracterizada por atrofia vilositária, hipertrofia de criptas e infiltrado linfocitário. O tratamento consiste de excluir o glúten da $\operatorname{dieta}^{(8)}$. A associação entre as doenças inflamatórias intestinais e o LES também é rara e, geralmente, o lúpus é diagnosticado primeiro. Quando a segunda doença se manifesta, a primeira costuma estar inativa. Os pacientes com LES e doença inflamatória intestinal costumam apresentar menos fotossensibilidade, menos serosite e não têm acometimento neurológico, quando comparados aos pacientes com LES somente. $\mathrm{O}$ anti-dsDNA é encontrado em grande parte dos pacientes com esta associação e há tendência a leucopenia e trombocitopenia. O prognóstico é melhor quando há associação, do que no lúpus isoladamente ${ }^{(9)}$. Entretanto, no Brasil foi relatado um caso de evolução fatal, em que a doença de Crohn foi diagnosticada primeiro ${ }^{(10)}$.

No Brasil, onde a tuberculose é infecção freqüente, o acometimento intestinal pode ocorrer de maneira isolada ou associada a manifestações sistêmicas, como febre, linfonodomegalia e comprometimento pulmonar. O quadro intestinal envolve diarréia, síndrome disabsortiva, perda de peso, náuseas, vômitos, melena e enterorragia. A região jejuno-ileal e o íleo terminal estão acometidos em mais de $75 \%$ dos casos, exibindo áreas de ulceração, hipertrofia ou estenose, o que dificulta seu diagnóstico diferencial com doença de Crohn. Poucas vezes se manifesta como colite tuberculosa, podendo ser confundida com a retocolite ulcerativa. A partir da suspeita clínica alguns exames auxiliam na confirmação diagnóstica, como PPD positivo, radiografia de tórax com infiltrado em ápice, trânsito de delgado e enema opaco com acometimento do íleo terminal e colo-

\section{REFERÊNCIAS}

1. Luangjaru S, Kullavanijaya P: Gastrointestinal and hepatobiliary manifestations in systemic lupus erythematosus. J Med Assoc Thai 88(1): 71-5, 2005.

2. Lian TY, Edwards CJ, Chan SP, Chng HH. Reversible acute gastrointestinal syndrome associated with active systemic lupus erythematosus in patients admitted to hospital. Lupus 12: 612-6, 2003.

3. Schiller LR: Chronic diarrhea. Gastroenterology 127(1): 287-93, 2004. noscopia com biópsia das lesões. A tomografia de abdome pode evidenciar hepatoesplenomegalia, linfonodomegalia e $\operatorname{ascite}^{(13)}$.

A estrongiloidíase pode ser assintomática, manifestar-se como diarréia crônica ou evoluir para quadros disseminados em imunossuprimidos ${ }^{(12)}$. A hiperinfecção pode simular doença inflamatória intestinal, apresentando-se como síndrome disabsortiva e colite à colonoscopia, ou levar a complicações, como a suboclusão intestinal ${ }^{(14)}$. Nos casos graves, a eosinofilia característica pode não estar presente. O diagnóstico é feito pela presença do Strongyloides stercoralis nas fezes e, em algumas situações, este parasita pode ser observado em biópsias de mucosas de lesões duodenais ou colônicas ${ }^{(12,14)}$.

Quando o paciente foi admitido na enfermaria de clínica médica, não houve suspeita diagnóstica de LES até que ele apresentasse o quadro neurológico que, em razão de sua gravidade, foi tratado com imunossupressão. Os exames de coprocultura e parasitológicos negativos afastaram as causas infecciosas e as parasitoses. Com a biópsia de duodeno e a relação vilo/cripta mantida, afastou-se a suspeita de doença celíaca e a coloração PAS negativa excluiu a hipótese doença de Whipple. Os exames de trânsito de delgado e enema opaco normais falavam contra o diagnóstico de doença inflamatória intestinal e tuberculose. Igualmente, a ausência de linfonodomegalia e hepatoesplenomegalia na tomografia de abdome não sugeria tuberculose. A enteropatia perdedora de proteínas seria pouco provável, pois o paciente apresentava proteinúria. É possível que o quadro intestinal fosse secundário à vasculite mesentérica, que respondeu prontamente ao tratamento da doença de base e remitiu juntamente com os sintomas neurológicos e o quadro renal.

Em conclusão, diarréia crônica pode ser manifestação inicial de LES e esse diagnóstico deve ser considerado principalmente nos casos em que haja indícios de envolvimento sistêmico.

4. Kishimoto M, Nasir A, Mor A, Belmont HM: Acute gastrointestinal distress syndrome in patients with systemic lupus erythematosus. Lupus 16: 137-41, 2007.

5. Versaci A, Macrì A, Scuderi G: Ischemic colitis following colonoscopy in a systemic lupus erythematosus patient: report of a case. Dis Colon Rectum 48(4): 866-9, 2005.

6. Park JM, Ahn SY, Shin JI, Yun MJ, Lee JS: A systemic lupus erythematosus patient with protein losing enteropathy. Yonsei Med J 45(5): 923-6, 2004. 
7. Mok CC, Ying KY, Mak A, To CH, Szeto ML: Outcome of protein-losing gastroenteropathy in systemic lupus erythematosus treated with prednisolone and azathioprine. Rheumathology 45: 425-9, 2006.

8. Mirza N, Bonilla E, Philips PE: Celiac disease in a patient with systemic lupus erythematosus: a case report and review of literature. Clin Rheumatol 26: 827-8, 2007.

9. Nitzan O, Elias M, Saliba WR: Systemic lupus erythematosus and inflammatory bowel disease. Eur J Int Med 17: 313-8, 2006.

10. Chebli JM, Gaburri PD, Souza AF, et al.: Fatal evolution of systemic lupus erythematosus associated with Crohn's disease. Arq Gastroenterol 37(4): 224-6, 2000.
11. Somasundaram KV, Sudhakar MK, Damodharan J, Kallarakkal JT, Sahib K, Mahajan A: An unusual presentation of systemic lupus erythematosus. J Indian Med Assoc 102(2): 97-9, 2004.

12. Yoshida H, Endo H, Tanaka S, Ishikawa A, Kondo H, Nakamura $\mathrm{T}$ : Recurrent paralytic ileus associated with strongyloidiasis in a patient with systemic lupus erythematosus. Mod Rheumatol 16(1): 44-7, 2006.

13. Horvath $\mathrm{KD}$, Whelan RL: Intestinal tuberculosis: return of an old disease. Am J Gastroenterol 93(5): 692-6, 1998.

14. Narciso-Schiavon JL, Martinez JD, Lemos LVB, Poletti PB, Sipahi HM, Guz B. Strongyloides hyperinfection simulating inflammatory bowel disease. GED 26 (4): 133-5, 2007. 